\title{
Data-driven environmental solutions for smart sustainable cities: strategies and pathways for energy efficiency and pollution reduction
}

\author{
Simon Elias Bibri ${ }^{1,2}$ \\ Published online: 30 October 2020 \\ (c) Springer Nature Switzerland AG 2020
}

\section{Introduction}

The concentration of economic activities, the high-intensity use of resources, and the massive deployment of nonrenewable energy in cities demonstrate that they have major negative impacts on the environment. In other words, the significance of the environment in cities is justified by the fact that they consume about $70 \%$ of global energy supply, generate about $75 \%$ of greenhouse gas (GHG) emissions, and have currently more than $50 \%$ of the world population, estimated to reach $70 \%$ by 2050 . In the current climate of unprecedented urbanization and increased uncertainty in the world, it is becoming increasingly more challenging for cities to configure themselves more sustainably from an environmental perspective (Bibri 2020a, b). Urban growth raises a variety of problems that jeopardize the environmental sustainability of cities as it puts an enormous strain on urban systems and thus great demand on energy resources and services. Energy produces the largest share of the world's emissions of greenhouse gases (GHG), which makes it the dominant contributor to climate change. With rising GHG emissions, climate change is occurring at rates much faster than anticipated and its effects are clearly felt worldwide (UN 2019a). The SDG 13 aims to take urgent actions to combat climate change (UN 2019b), which largely relate to the energy domain of cities.

Nonetheless, modern cities play a leading role in strategic sustainable development and have a central position in developing and applying advanced technologies to

Simon Elias Bibri

simoe@ntnu.no

1 Department of Computer Science, The Norwegian University of Science and Technology, Sem Saelands veie 9 , 7491 Trondheim, Norway

2 Department of Architecture and Planning, The Norwegian University of Science and Technology, Alfred Getz vei 3, Sentralbygg 1, 5th floor, 7491 Trondheim, Norway support the progress towards environmental sustainability in the face of the escalating urbanization trend. The United Nation's 2030 Agenda regards advanced information and communications technology (ICT) as a means to protect the environment, increase resource efficiency, achieve human progress and knowledge, and upgrade legacy infrastructure (UN 2015a). Therefore, the multifaceted potential of the smart city approach has been under investigation by the UN (2015b) through their study on "Big Data and the 2030 Agenda for Sustainable Development." This is of high importance and relevance to the Sustainable Development Goal 7 (SGD 7) of the UN's 2030 Agenda (UN 2019b): "ensure access to affordable, reliable, sustainable, and modern energy for all" (UN 2019a). Energy is at the core of sustainable development goals, and thus the modernization of energy systems is more needed than ever.

Currently, greater importance is given to economic development and social development at the cost of environmental integration and protection. In recent years, major topics discussed in this area have included the depletion of nonrenewable resources, the harvesting of renewable resources, the destruction of ecosystems, and the generation of pollution. Therefore, advanced computational data analytics approaches are required to observe and discover hidden patterns of energy production and consumption in order to devise more effective solutions that could avert the multidimensional effects of devouring energy. There is a general consensus and practical evidence that data-driven technology solutions play a key role in improving energy efficiency and reducing pollution in both sustainable cities and smart cities (e.g., Bibri and Krogstie 2020a) within the framework of smart sustinable cities. Indeed, big data technology is seen as a critical enabler for advancing environmental sustainability given its unique ability to make energy consumption and GHG emissions visible through its processes, products, and services. Big data analytics techniques are gradually replacing the traditional mechanisms of urban management, with the aim to improve the quality and speed of decision-making 
pertaining to a wide range of practical uses and applications thanks to real-time analysis. Big data technology has become as essential to the functioning of smart cities (e.g., Angelidou et al. 2017; Bibri 2019a, 2020a; Bibri and Krogstie 2020b; Kumar and Prakash 2016; Nikitin et al. 2016) as to that of sustainable cities (e.g., Bibri 2018, 2019b, c, 2020a, b; Bibri and Krogstie 2020c; Shahrokni et al. 2014; Shahrokni, Levihn and Brandt. 2014; Shahrokni et al. 2015a; Shahrokni, Lazarevic and Brandt 2015) in the endeavor to optimize and enhance their performance with respect to environmental sustainability. This relates to what has recently been termed "environmentally data-driven smart sustainable cities" (Bibri and Krogstie 2020a) where the vision of smart energy and smart environment has spurred the development of new approaches to smart energy systems and environmental control and monitoring systems.

\section{Resource efficiency and climate responsibility strategy and its substrategies}

One of the overarching strategies of the leading environmental programs for smart sustainable cities is "resource efficiency and climate responsibility." (Bibri and Krogstie 2020a, c) With this strategy, smart sustainable cities aim to reduce GHG emissions to a level below 1 ton per inhabitant by 2030 and to become fossil fuel-free and climate-positive by 2050 as ambitious environmental goals. At the core of this strategy is the reduction of energy consumption and carbon footprint as well as the use of digitalization and new technologies to make it easier for citizens and businesses to be environmentally friendly.

Both smart cities and sustainable cities are increasingly investing in and implementing smart meters, sensor networks, automated control systems, and cyber-physical systems in the area of smart energy and smart environment within the framework of the Internet of Things (IoT). The main four substrategies of the resource efficiency and climate responsibility strategy associated with smart energy and smart environment are detailed next.

\section{Smart grid and advanced metering infrastructure}

The goal of smart energy is to achieve energy systems that are highly energy efficient, increasingly powered by renewable and local energy sources enabled by new technologies, and less dependent on fossil fuels. The main players in the area of smart energy are smart power grid and advanced metering infrastructure (including smart meters). Smart power grid denotes a set of hardware, software, and network tools which enable generators to route power more efficiently to consumers, reducing the need for excess capacity and allowing two-way communication for real-time demand side management. It collects the data received from the Wi-Fi-enabled sensor network on the level of power supply from diverse sources and then processes and analyzes these data in real time for decisionmaking and information transmission for process control to improve the performance of the power grid. Advanced metering infrastructure denotes a composite technology which consists of solid-state meters capable of remotely providing consumers' electricity use detail (i.e., electric energy, voltage levels, current, power factor) to the utility, a two-way communications channel (i.e., to power suppliers for system monitoring and billing and to consumers for greater clarity of consumption behavior), and a meter data repository and management. Thus, it includes sensors placed on consumers access points and on production, transmission, and distribution systems, as well as remote controls and communication technologies within electricity networks. The operational functioning of the smart grid system involves ICT system integration, data, and back office, which allow the integration of front-end engineering, middleware, and computing systems, as well as data collection and decision analytics (Bibri 2020b). This is part of the overall IoT infrastructure of smart sustainable cities in terms of horizental information system and operations center. Typically, the operations center serves to monitor the city as a whole; to draw together real-time data streams from many different city agencies and departments into a single hub; and to process, visualize, and monitor the vast deluge of live service data for real-time decision-making and problem-solving. It includes automated systems of response to city-wide events (e.g., control rooms) pertaining to energy and environment, among others.

The key pathways (or tactics) needed for executing the smart grid and advanced metering infrastructure strategyintegrating and coordinating renewable energy production and consumption and power facilities through enabling technologies, energy services, and active users-are:

- Support projects of smart grid technologies.

- Subsidize projects that support energy-efficiency technology adoption.

- Allow decentralization of energy production.

- Encourage energy production from renewable sources.

- Promote the multiplication of grid distribution networks.

- Subsidize projects that incorporate integrate renewable energy in power distribution networks.

- Develop and implement integrated renewable solutions which involve the use of modelling, simulation, analytical, and management tools to enable a wide deployment of renewable energy. 
- Deploy and Implement a large-scale smart grid system:

- Smart homes/buildings and demand response.

- Distributed energy systems.

- Energy storage for the grid and consumers.

- Smart primary substations.

- Smart grid as part of innovation lab.

- Integration and use of electric vehicles.

\section{Smart buildings}

The building management system (BMS) is primarily intended to maintain predefined parameters (or set points) and the control of their functionality. It uses smart metering and advanced visualization tools to provide real-time monitoring and continuously gather the data on what is taking place in a building and how its equipment is operating and feeding them into a control system to optimize performance. So, the collected data can be used to identify additional opportunities for energy efficiency improvements. Below are the key pathways needed for executing the smart building strategy:

- Subsidize design projects that support efficiency technology adoption and expansion among building owners and operators as well as urban developers.

- Reward the best-in-class buildings' owners and operators as well as urban developers.

- Provide funding schemes that encourage owners to invest in building automation systems.

- Develop and implement assessment tools for energyefficient building.

- Regulate the use of automation measures in the construction of buildings and new development projects.

- Use decision-support systems which enable large-scale energy efficiency improvements in existing building stock.

- Evaluate the energy efficiency potential of different building vintages in collaboration with utility companies in the different districts of the city to reduce energy use, depending on the market segmentation pertaining to the date of the construction of buildings.

- Use data-driven smart approach to strategic planning of building energy retrofitting, using data about actual building energy consumption, energy performance certificates, reference databases, and so forth. This allows a holistic city-level analysis of retrofitting approaches and strategies thanks to the aggregated projections of the energy performance of each building, such as energy saving, emissions reduction, and required family or social investment.
- Install BMS in new and retrofitted municipal, commercial, and industrial buildings to monitor and optimize the use of the supervised subsystems.

\section{Smart home appliances and devices}

Smart homes allow homeowners to control appliances, lights, and other devices remotely using a smartphone through an internet connection. Smart home technology provides homeowners with convenience and cost savings. A smart appliance or device includes the intelligence and communications to enable automatic or remote control based on user preferences or external signals. The key pathways needed for executing the smart home appliances and devices strategy are:

- Promote and install energy star heating, ventilation, and air conditioning (HVAC) systems in municipal, commercial, industrial, and residential buildings.

- Promote and install energy star appliances which use a great deal less power than their predecessors.

- Promote and install smart power strips which sense energy demand and cut off power supply to fully charged or not in use devices.

- Promote and install smart meters to allow:

- Consumers to manage their energy usage based on what they actually need and afford by having access to live energy prices and adjusting their usage accordingly.

- Consumers to remotely control their home appliances and devices by means of such advanced functions as scheduling, programming, as well as reacting to different contextual situations.

- Self-optimize and self-control energy consumption through integrating sensing and actuation systems in different kinds of appliances and devices for balancing power generation and usage.

- Provide insights into how the energy flows can be influenced by the consumer behavior thanks to the in-house sensors that can provide data on energyusing appliances.

- Promote and install easy-to-use home energy monitoring systems (HEMS) which present useful information on energy usage directly to the consumer's devices, allowing them to change their behavior as well as save money in the long run. HEMS also offer homeowners more options than smart meter-to-smart appliance connections, e.g., a sophisticated level of preprogrammed preferences in terms of turning on some appliances based on the amount of the energy consumed within a day, week, or month. 
- Promote and install energy monitoring software on smartphones in case the smart meter is already installed in the house so as to allow one to read the information collected by the smart meter.

- Install energy monitoring systems in municipal buildings for obtaining information about energy consumption, such as electricity meter, electricity ambient conditions, internal ambient conditions, and temperature.

\section{Environmental control and monitoring}

Air pollutants as atmospheric substances-especially anthropogenic - have negative impacts on the environment, as well as pose a high environmental risk to human health, so too is noise pollution, both direct and indirect. Noise pollution denotes harmful outdoor sound with road traffic being the greatest contributor. The demand for the smart systems that monitor the quality of the environment has increased because of the elevation of pollutants in the atmosphere The escalating urbanization trend leads to the environmental degradation of the air. Nonetheless, new technologies allow a real-time tracking capability of the different substances spread in the air, as well as applying preventive measures in a timely manner. For smart cities and sustainable cities to have the best air quality, they must significantly reduce GHG emissions from their energy and transport domains and become zero-carbon. One of the significant objectives of smart sustainable cities is to achieve a healthy and hyperconnected cities with zero emissions where urban planning, the environment, and ICT infrastructures are fully integrated and chracterized by productive neighborhoods (Bibri and Krogstie 2020a). Many recent studies address the impacts of energy consumption on the environment and on control over transport flows and their effects on the noise level (e.g., Angelidou et al. 2017; Bibri 2020a; Bibri and Krogstie 2020b; Nikitin et al. 2016).

Important to note is that the environmental monitoring strategy is complementary to the smart grid and advanced metering infrastructure strategy, which is indeed designed to control GHG emissions. Smart environmental control systems in smart sustainable cities can help to collect critical information to make better policy decisions to reduce GHG emissions. They can also guide citizens on making their own efforts to reduce GHG emissions. However, the key pathways needed for executing the environmental control and monitoring strategy are:

- Develop and implement more effective mechanisms to get consumers and producers to use innovative solutions to reduce GHG emissions to levels that are economically, environmentally, and socially sustainable.
- Develop and implement environmental control systems associated with energy efficiency (e.g., smart meters, smart sensors, automation devices, monitors, etc.).

- Develop and implement environmental control measures for preventing GHG emissions.

- Convert the small-scale tests performed in the areas of air pollution and noise pollution into pilot projects and then transition to large-scale deployments and implementations.

- Devise and implement solutions for control over air pollution which analyze the data collected from sensors on the level of air pollution in the different districts of the city.

- Develop and implement different prevention systems, including monitoring, forecasting, and modelling based on artificial neural networks, i.e., computing systems inspired by biological neural networks and based on a collection of connected nodes called artificial neurons, for enhancing decision-making to remove different types of pollutants detrimental to public health.

- Facilitate the operation of the air quality monitors by regulatory agencies, citizens, as well as researchers to investigate the air quality and the effects of air pollution.

- Devise and implement solutions for noise pollution control which analyze the data collected from sensors on the level of noise pollution for planning of work to reduce it. Such solutions should enable to optimize and centralize the collection, integration, processing, and dissemination of information by the noise sensors of different suppliers and sound level meters distributed throughout the city. The fine-grained information of noise can inform people's daily decision-making as well as policymakers on tackling noise pollution.

- Use the data recorded by the various sensors connected to the city's Wi-Fi network and reporting in real time such parameters as air quality, noise levels, temperature, humidity, and gas dust particles concentrated in particular urban environments to analyze the impacts of the measures taken to improve the state of the environment, to make inferences about the quality of the air, to compile further programs for environment protection, and to identify the areas where further actions are to be undertaken.

- Create living labs for environmental monitoring management which provide a variety of services by using sensors to measure a range of physical parameters. The active sensors recording the relative and appropriate information for the services should be spread across the different zones of the city for obtaining the accurate data for these services. Use the collected data to increase the knowledge of the most important city problems that need to be solved. 
- Develop and implement an integrated automated environmental protection system in the city. The results of measurements should be published in online platforms to be visited by special software developers on a monthly basis.

- Promote easy to use and set up hardware and software for environmental monitoring systems (sensors and base units) among businesses, organizations, and institutions to:

- Measure and log a range of environmental conditions (e.g., relative humidity, temperature, differential pressure, pressure, flow, lux, and carbon dioxide) in real time.

- Track and provide early warnings in case of critical events or unfavorable conditions before they turn into disasters.

- Provide various solutions for environmental monitoring with regard to server rooms, data centers, storage facilities, and laboratories to organizational and institutional units, as well as to those related to the ICT infrastructure of the city, such as horizental information platforms, analytical centers, and operations centers.

- Commit to further developing and advancing environmental monitoring technologies and enhancing their applications in the future to guarantee a maximized effect of the use of the information collected about the state of the environment. This is due to the challenges of enacting environmental monitoring, notably the effective integration of multiple environmental data sources originating from different environmental networks and institutions. Such integration requires specialized observation equipment, tools, techniques, and models to establish air pollutant concentrations at different spatial and temporal scales.

\section{Summary}

Data-driven smart solutions have significant potential to improve and advance environmental sustainability in the context of smart sustainable cities, notably smart grid, advanced metering infrastructure, smart buildings, smart home appliances and tools, and smart environmental control and monitoring. There is a clear synergy between these solutions in terms of their interaction to produce combined effects greater than the sum of their separate effects with respect to the environment.

Smart grid technologies provide numerous benefits associated with energy use optimization, energy management, energy conservation, cost reduction, as well as the integration of alternative energy sources in power generation, transmission, and distribution systems. They allow bidirectional energy flows and information between suppliers and consumers and provide data on real-time usage and energy pricing. This in turn provides numerous advantages, including real-time visibility, service reliability, control of cost and electricity usage, shift in peak load, capacity requirement of the grid, and energy production and sharing (prosumer). Similarly, smart building technologies have proven to be effective in curbing energy consumption. They can provide a multifunctional role in energy efficiency and GHG emission reductions through highly advanced automatic systems for efficient and natural lighting, temperature control, window and door operation, electric appliances, and many other functions. BMS allows more efficient operation, keeps the building's climate within a specified range, reduces energy consumption, reduces energy costs, and guarantees safety and security.

The different methods of collecting information about the quality of the air and the presence of harmful substances therein have recently undergone major advances thanks to the IoT. Related sensor systems are able in real time to gather data about the condition of the air in the different parts of the city and to transmit these data to special data analytical centers for processing and analysis. Moreover, it is possible now to produce a comprehensive analysis of the collected data, which allows the public authorities to observe the condition of the air and to forecast about its pollution on the basis of such analysis by means of sophisticated modelling and simulation systems. This is to effectively build a variety of preventive systems for environmental protection, as well as to inform citizens and other city stakeholders.

Policy plays an important role in addressing and overcoming the barriers to the development of smart grids, including the deployment of advanced metering infrastructure, as well as to the adoption of smart building technology. In fact, policy remains more important than technology in the context of smart sustainable cities. Most of the data-driven smart solutions that are being rolled out are only "plasters" that fail to address the wider environmental issues of climate change. This means that policy must be put into place to maximize the benefits of such solutions through more effective measures. Smart sustainable cities should have a set of specific policy frameworks to ensure that progress is made in any area of environmental sustainability where innovative solutions need to be implemented. Moreover, the new policy frameworks that aim to encourage or require the use of advanced ICT to mitigate climate change should be evaluated carefully in terms of their ability to absolutely reduce GHG emissions, not merely to slow down their rate of increase. Appropriate policy frameworks can provide the incentives needed to act and innovate to curb energy use and alleviate pollution levels. However, policy tools should 
include both incentives and prohibitions through a mixture of regulation, co-regulation, and self-regulation; top-down and bottom-up approaches to policy development and implementation; and governance arrangements that engage all stakeholders in their roles as citizens and consumers.

\section{References}

Angelidou M, Psaltoglou A, Komninos N, Kakderi C, Tsarchopoulos P, Panori A (2017) Enhancing sustainable urban development through smart city applications. J Sci Technol Policy Manag 9(2): 146-169

Bibri SE (2018) The IoT for smart sustainable cities of the future: an analytical framework for sensor-based big data applications for environmental sustainability. Sustain Cities Soc 38:230-253

Bibri SE (2019a) On the sustainability of smart and smarter cities in the era of big data: an interdisciplinary and transdisciplinary literature review. J Big Data 6(25):2-64

Bibri SE (2019b) Big data science and analytics for smart sustainable urbanism: unprecedented paradigmatic shifts and practical advancements. Springer, Germany, Berlin

Bibri SE (2019c) The anatomy of the data-driven smart sustainable city: instrumentation, datafication, computerization and related applications. J Big Data 6:59

Bibri SE (2020a) Advances in the leading paradigms of urbanism and their amalgamation: compact cities, eco-cities, and data-driven smart cities, vol 2020. Springer, Cham

Bibri SE (2020b) The eco-city and its core environmental dimension of sustainability: green energy technologies and their integration with data-driven smart solutions. Energy Inform. https://doi. org/10.1186/s42162-020-00107-

Bibri SE, Krogstie J (2020a) Environmentally data-driven smart sustainable cities: applied innovative solutions for energy efficiency, pollution reduction, and urban metabolism. Energy Inform. https ://doi.org/10.1186/s42162-020-00130-8

Bibri SE, Krogstie J (2020b) The emerging data-driven smart city and its innovative applied solutions for sustainability: the cases of London and Barcelona. Energy Inform. https://doi.org/10.1186/ s42162-020-00108-6

Bibri SE, Krogstie J (2020c) Smart eco-city strategies and solutions: the cases of Royal Seaport, Stockholm, and Western Harbor, Malmö Sweden. Urban Sci 4(1):1-42

Kumar A, Prakash A (2016) The role of big data and analytics in smart cities. Int J Sci Res (IJSR) 6(14):12-23

Nikitin K, Lantsev N, Nugaev A, Yakovleva A (2016) Data-driven cities: from concept to applied solutions. Pricewater- houseCoopers (PwC).. http://docplayer.net/50140321-From-concept-to-appli ed-solutions-data-driven-cities.html.

Shahrokni H, Levihn F, Brandt N (2014) Big meter data analysis of the energy efficiency potential in Stockholm's building stock. Energy Build 78:153-164

Shahrokni H, Årman L, Lazarevic D, Nilsson A, Brandt N (2015) Implementing smart urban metabolism in the Stockholm Royal Seaport: Smart city SRS. J Ind Ecol 19(5):917-929

Shahrokni H, Lazarevic D, Brandt N (2015) Smart urban metabolism: towards a real-time understanding of the energy and material flows of a city and its citizens. J Urban Technol 22(1):65-86

United Nations (2015a) Habitat III issue papers, 21-Smart cities (V2.0), New York, NY. Retrieved May 2, 2017, from https://colla boration.worldbank.org/docs/DOC-20778.

United Nations (2015b) Big data and the 2030 agenda for sustainable development. Prepared by A. Maaroof. https://www.unescap.org/ events/call-participants-big-data-and-2030-agendasustainabledevelopment-achieving-development

United Nations (2019a) The energy progress report. https://trackingsd g7.esmap.org

United Nations (2019b) Sustainable development Goal 13. https://susta inabledevelopment.un.org/sdg 13 